\title{
Composition of uroliths in a tertiary hospital in South East Nigeria
}

\author{
Ijeoma A Meka, Martin C Ugonabo, Samuel O Ebede, Ezra O Agbo
}

Department of Chemical Pathology, University of Nigeria Teaching Hospital, Ituku-Ozalla, PMB 01129, Enugu, Enugu State, Nigeria.

\section{Emails and telephone numbers:}

1. Ijeoma A. Meka: Email: ijeamaka20@gmail.com

Phone: +2347030967673

2. Martin C. Ugonabo: Email: amimigee41@yahoo.com

Phone: +2348077839234

3. Samuel O. Ebede: Email: dronnyebede@yahoo.com

Phone: +2348036664441

4. Ezra O. Agbo: Email: ezradragbo@yahoo.com

Phone: +2348030995886

\begin{abstract}
Background: Urolithiasis affects primarily the urinary tract and complications as debilitating as renal failure may develop. Determining the chemical composition of uroliths can aid management and prevention of recurrence in patients.

Objective: To determine the chemical composition and anatomical distribution of uroliths in Nigeria.

Methods: This descriptive cross-sectional study was conducted between March 2014 and February 2016, in a tertiary hospital in Nigeria. We reviewed the outcomes of uroliths of adult patients sent to our laboratory for chemical analyses. Samples were analyzed using simple qualitative tests.

Results: 52 adult patients were included with a mean age (SD) of $46.6(12.6)$ years. Males $(76.9 \%)$ were more affected than females (23.1\%). For both sexes, highest occurrence of stones was in bladder $(85.7 \%)$. Calcium-containing stones had the highest occurrence $(85.2 \%)$ and predominated in the renal, ureter and urethra, followed by struvite stones $(59.5 \%)$. In the bladder, struvite stones were predominant $(85.8 \%$ ), with calcium-containing stones accounting for $71.4 \%$.

Conclusion: This study showed that struvite and calcium phosphate-containing stones constitute majority of uroliths in our setting with low occurrence of calcium oxalate stones. This indicates that urinary tract infection most likely plays a substantial role in the formation of uroliths in Nigerians. Modern methods of stone analysis is advocated to further define management options.
\end{abstract}

Keywords: Uroliths, calcium oxalate, chemical composition, struvite, stone, calculi.

DOI: https://dx.doi.org/10.4314/ahs.v18i2.29

Cite as: Meka LA, Ugonabo MC, Ebede SO, Agbo EO. Composition of uroliths in a tertiary hospital in South East Nigeria. Afri Health Sci. 2018;18(2): 437-445. bttps://dx.doi.org/10.4314/abs.v18i2.29

\section{Corresponding author:}

Ijeoma A Meka, Department of Chemical Pathology, University of Nigeria Teaching Hospital, Ituku-Ozalla, PMB 01129, Enugu, Enugu State, Nigeria

Phone: +2347030967673

Email: ijeamaka20@gmail.com

\section{Introduction}

Urolith simply means a calculus or stone in the urinary tract and hence comprises renal, ureteral, bladder and urethral calculi. These are solid masses formed in the urinary tract from minerals in urine. They represent an age long medical condition which places an appreciable disease burden on the global populace. The prevalence and incidence of stone diseases particularly kidney stones, is reported to be increasing worldwide and these increases

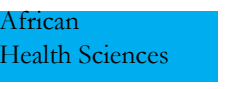

(C) 2018 Meka et al. Licensee African Health Sciences. This is an Open Access article distributed under the terms of the Creative commons Attribution License (https://creativecommons.org/licenses/by/4.0), which permits unrestricted use, distribution, and reproduction in any medium, provided the original work is properly cited. 
are seen across sex, age and race. ${ }^{1}$ In the United States in 2012, ${ }^{2}$ kidney stones were reported to affect 1 in 11 people representing a marked increase in stone disease particularly in Black, non-Hispanic and Hispanic individuals. In Germany, ${ }^{3}$ an increase in prevalence of urolithiasis was reported from 4\% in 1979 to $4.7 \%$ in 2001 with the recurrence rate estimated to be $42 \%$. In a tertiary health care centre in Nigeria, between 1980 and 1986, ${ }^{4}$ an increase in prevalence of urolithiasis was reported. Two independent studies also reported incidences of $13^{5}$ and $6.3^{6}$ per 100,000 patients in two different tertiary health care centres in Nigeria.

With these documented increases in prevalence of stone disease, determination of composition of uroliths is of great importance to provide insight to the etiology of the stone and hence the management and prevention of recurrence. Stone composition varies greatly but calcium oxalate, calcium phosphate, uric acid, struvite (magnesium ammonium phosphate), and cystine are the most common urinary stone types. Some of the risk factors associated with urolithiasis include , $23,27,29$ dehydration, family history, obesity, prior occurrence, urinary tract infection, metabolic disorders like gout, hyperparathyroidism, drugs like diuretics, among others.

It has been documented that stone disease is commoner in Whites than Blacks ${ }^{8,9}$ but the associated pain and morbidity may not differ. Hence there is need to regularly update the frequency, anatomical distribution, and composition of stones in persons at-risk of forming urinary stones in the Black population especially in resource-limited settings like Nigeria where treatment is still predominantly by open surgery. This is essential to limit recurrence rates and frequency of surgical interventions with the attendant pain and possible complications.

In South-East, Nigeria, the last and only available attempt at this characterization was 32 years ago by Mbonu et $\mathrm{al}^{5}$, hence the necessity of this study to determine the anatomical distribution and composition of uroliths in a sub-population of Black patients.

\section{Materials and methods \\ Study location}

This was a $3 \frac{1}{2} 2$-year descriptive cross-sectional study conducted at the department of Chemical Pathology, University of Nigeria Teaching Hospital (UNTH), Enugu, a tertiary health institution in South-East Nigeria, between March, 2014 and February, 2016. UNTH is a 576 bedded hospital serving Enugu, Anambra and Abia states, all states in the South-East geopolitical zone of Nigeria. The inhabitants of these states are mainly indigenes of Igbo extraction, whose main occupation are farming and trading with a small proportion subsisting as civil servants.

\section{Study population}

The study was carried out using uroliths from consecutively selected consenting adult patients aged 18 years and above, who had surgery for urinary tract stone removal and the stone(s) sent for chemical analysis within the study period.

\section{Study design}

Prior to chemical analysis, the stones were washed with distilled water, air dried and weighed.

Each stone was then cut into two and examined for a nucleus. Presence of a nucleus required separate analysis of nucleus and periphery. The stone was then crushed using a porcelain mortar and pestle and the powdered form subjected to chemical analysis using the McIntosh and Salter method ${ }^{10}$. Patients' records were carefully reviewed for age, sex, race and location of stones.

\section{Inclusion criteria}

All consenting adult patients aged 18 years and above who had surgery for urinary tract stone and the stones sent for chemical analysis during the study period.

\section{Exclusion criteria}

Paediatric patients, adult patients with gall-bladder stones and patients declining consent.

\section{Ethical considerations}

Written informed consent was obtained from participants and ethical clearance obtained from UNTH Health Research and Ethics Committee with reference number $\mathrm{UNTH} / \mathrm{CSA} / 329 / 5$.

\section{Statistical analysis}

Data was analyzed using SPSS version 20 and reported as frequencies for categorical variables, and mean (standard deviation) for continuous variables. Chi-square test was used to compare categorical variables. A p-value $<0.05$ was used to denote statistical significance. 


\section{Results}

During the study period, 54 uroliths were received from 52 patients aged 18 years and above (one patient had 3 stones from different anatomical locations; renal, ureter and bladder). All participants were Blacks from South East, Nigeria. Mean age (SD) in years was 46.6 (12.6).

More males $(76.9 \%)$ were affected than females $(23.1 \%)$ with a Male to Female ratio of 3.3:1.

Patients who fell within the $30-49$ years age group had the highest number of stones in both males and females (50\% each). The age and sex distribution of the urinary stones is as shown in Table 1 . The anatomical location of the urinary stone varied according to sex and age groups of the patients though these variations were not statistically significant, $\chi 2=3.69(3, \mathrm{~N}=52) \mathrm{p}=0.3$ and $\chi^{2}=8.64$ (3, N=52) $\mathrm{p}=0.47$ respectively. In females, $50 \%$ of the stones occurred in the bladder and $41.7 \%$ were ureteric stones (Fig 1). In males, 35.7\% were bladder stones followed by renal stones $(31.0 \%)$, and ureteric stones $(21.4 \%)$. All the age groups, except those within the 50 - 69 age group, had the highest number of stones occurring in the bladder. The anatomical locations of the stones according to sex is as shown in Fig 1 while Table 2 shows the anatomical locations according to age groups.

Table 1: Age and Sex distribution

\begin{tabular}{|l|l|l|l|}
\hline Age group (years) & Male & Female & Total \\
Number (\%) & Number (\%) & Number (\%) \\
\hline $18-29$ & $3(7.5)$ & $2(16.7)$ & $5(9.6)$ \\
\hline $30-49$ & $20(50.0)$ & $6(50.0)$ & $26(50.0)$ \\
\hline $50-69$ & $14(35.0)$ & $4(33.3)$ & $18(34.6)$ \\
\hline 70 and above & $3(7.5)$ & $0(0.0)$ & $3(5.8)$ \\
\hline Total & $40(100)$ & $12(100)$ & $52(100)$ \\
\hline
\end{tabular}




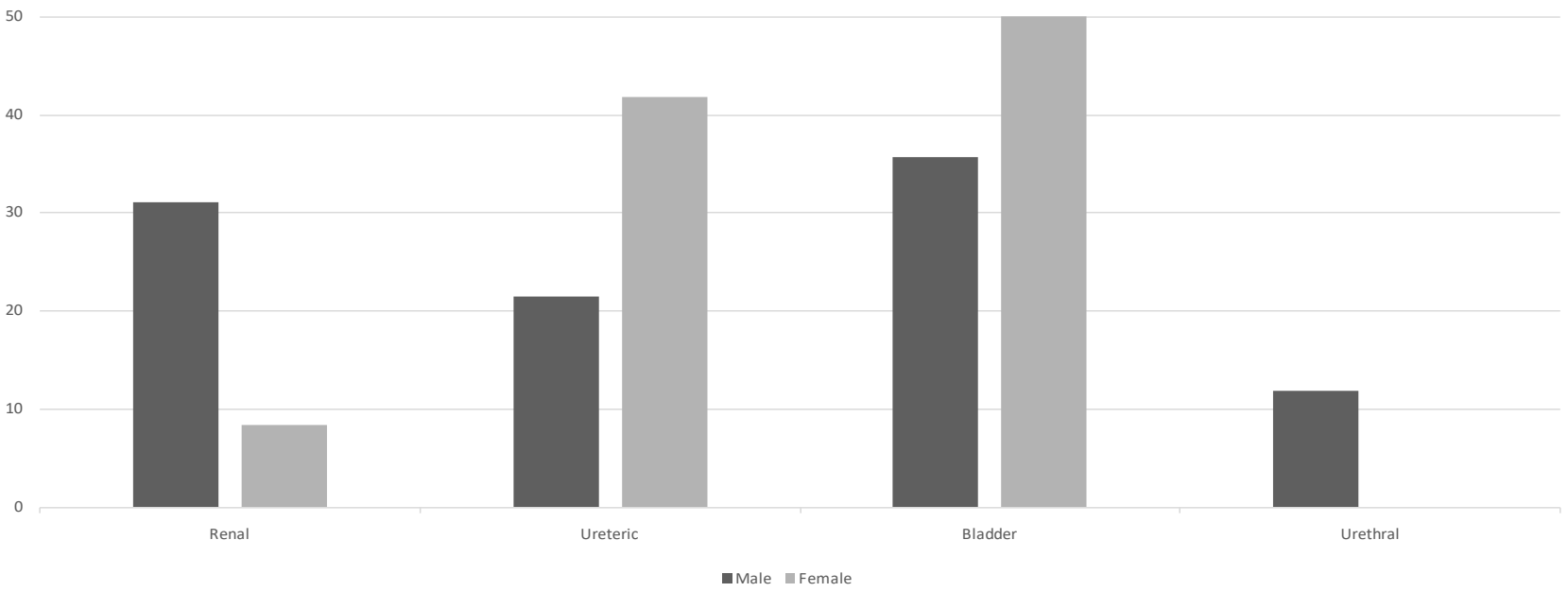

Fig 1: Stone anatomical location according to sex

Table 2: Stone anatomical location according to age groups

\begin{tabular}{|c|c|c|c|c|}
\hline \multirow[t]{2}{*}{ Age group(years) } & \multicolumn{3}{|c|}{ Anatomical location } & \\
\hline & $\begin{array}{l}\text { Renal } \\
\text { Number (\%) }\end{array}$ & $\begin{array}{l}\text { Ureter } \\
\text { Number (\%) }\end{array}$ & $\begin{array}{l}\text { Bladder } \\
\text { Number (\%) }\end{array}$ & $\begin{array}{l}\text { Urethra } \\
\text { Number (\%) }\end{array}$ \\
\hline $18-29$ & - & - & $3(5.8)$ & $2(3.8)$ \\
\hline $30-49$ & $5(9.6)$ & $8(15.4)$ & $12(23.1)$ & $3(5.8)$ \\
\hline $50-69$ & $9(17.3)$ & $6(11.5)$ & $3(5.8)$ & - \\
\hline 70 and above & - & - & $3(5.8)$ & - \\
\hline
\end{tabular}

NB: Total above $100 \%$ due to individuals with multiple stones 
All stones, $52(100 \%)$ were found to be of mixed composition, no pure stone was encountered. Calcium-containing stones had the highest occurrence $(85.2 \%)$ as all the stones analyzed with the exception of magnesium ammonium phosphate (Struvite) stones occurring alone contained calcium.

Interestingly, among the calcium-containing stones, calcium phosphate stones had the highest occurrence of $63.1 \%$ either alone or in combination. Stones containing Magnesium Ammonium Phosphate either alone or in combination constituted 59.5\%. No uric acid, xanthine or cystine stones were found. Composition of bladder stones having the highest occurrence in both sexes was analyzed separately. Magnesium ammonium phosphate either alone or in combination accounted for the highest occurrence $(85.8 \%)$. Calcium-containing stones accounted for $71.4 \%$ among which $52.5 \%$ contained calcium phosphate in combination with other ions. Table 3 shows the chemical composition of all the stones while Table 4 shows the chemical composition of the bladder stones.

Table 3: Chemical composition of Stones

\begin{tabular}{|c|c|c|}
\hline $\mathbf{S} / \mathbf{N}$ & Constituents & Number (\%) \\
\hline 1 & Calcium oxalate + Magnesium Ammonium Phosphate & $6(11.5)$ \\
\hline 2 & Calcium phosphate + Magnesium Ammonium Phosphate & $24(46.2)$ \\
\hline 3 & Calcium oxalate + Calcium phosphate + Magnesium & $1(1.9)$ \\
\hline 4 & Calcium phosphate + Ammonia & $5(9.6)$ \\
\hline 5 & Magnesium Ammonium Phosphate alone & $8(15.4)$ \\
\hline 6 & Calcium + Ammonia + Magnesium & $5(9.6)$ \\
\hline 7 & Calcium phosphate alone & $2(3.8)$ \\
\hline 8 & Calcium phosphate + Carbonate + Ammonia & $1(1.9)$ \\
\hline 9 & Calcium phosphate + Magnesium & $1(1.9)$ \\
\hline 10 & Calcium + Ammonia & 1 (1.9) \\
\hline
\end{tabular}

NB: Total above $100 \%$ due to individuals with multiple stones 
Table 4: Chemical composition of bladder stones

\begin{tabular}{|l|l|l|}
\hline S/N & Constituents & Number (\%) \\
\hline 1 & Calcium oxalate + Magnesium Ammonium Phosphate & $3(14.3)$ \\
\hline 2 & Calcium phosphate + Magnesium Ammonium Phosphate & $9(42.9)$ \\
\hline 3 & Calcium oxalate + Calcium phosphate + Magnesium & $1(4.8)$ \\
\hline 4 & Calcium phosphate + Ammonia & $1(4.8)$ \\
\hline 5 & Magnesium Ammonium Phosphate alone & $6(28.6)$ \\
\hline 6 & Calcium + Ammonia + Magnesium & $1(4.8)$ \\
\hline & & $21(100)$ \\
\hline
\end{tabular}

\section{Discussion}

The number of uroliths found in this study within the study period corroborates previous findings that urinary tract stones are commoner in Whites than in Blacks ${ }^{8,9}$. This is further corroborated by a study done in Ghana ${ }^{11}$ which reported a total of fifty-one patients with newly diagnosed upper urinary tract stones seen over an eight (8) year period, giving an incidence of 2 per 100,000. Again, it is generally accepted that urinary calculi occur more in males and the greater percentage of affected males seen in this study corroborates this. The male to female ratio of $3.25: 1$ seen in this study is similar to $4: 1$ recorded by Monu $^{6}$ in Benin, Nigeria. Studies in Northern Nigeria ${ }^{12}$ and Kenya ${ }^{13}$ also recorded preponderance of the disease in males. The age group with the highest percentage of stone formers in this study, $30-49$ years is similar to the
$31-40$ year age group recorded by Mbonu et $\mathrm{al}^{5}$ and $30-$ 40 year age group recorded in Nairobi ${ }^{14}$. And also similar to the peak age of 38 years recorded by Rahman et al ${ }^{15}, 30$ - 39 age group recorded in Saudi Arabia ${ }^{16}$ and 30 - 44 year age group recorded by Channa et $\mathrm{al}^{17}$. The reason for the high incidence in this age group is not clear, but urinary tract infections, dietary factor and obesity may be strong possibilities. Individuals in this age group are more likely to be sexually active and there is evidence ${ }^{18,19}$ to suggest that sexual activity predisposes to urinary tract infection in both pre- and post-menopausal women. High intake of calorie-rich drinks, low water intake, excess calorie intake consequently results in obesity which is also associated with stone formation ${ }^{20,21}$. Recent studies have indicated an increase in the prevalence of obesity and overweight in Nigeria $^{22,23}$ and Desalu et $\mathrm{a}^{24}$ further recorded the highest prevalence to be in the $40-49$ years age group. 
Bladder calculi were of the highest frequency in both sexes. This corroborates the findings of Mbonu et $\mathrm{al}^{5}$ previously done in the same region of Nigeria, and Jarrar et $\mathrm{al}^{16}$, which also recorded highest frequency of stones in the bladder and further buttresses the fact that bladder stones are still common in developing countries unlike in the western world ${ }^{25}$. This however differs from the studies in Maiduguri, Northern Nigeria, ${ }^{12}$ and Kenya ${ }^{13}$ which recorded higher frequency of stones in the upper urinary tract.

The composition of the bladder stones in this study shows predominance of magnesium ammonium phosphate (struvite) stones, also known as infection stones. These infection stones are usually secondary to urinary tract infection with a urease-producing organism, such as Proteus spp or Klebsiella spp. Urease catalyzes the hydrolysis of urea to produce ammonia, elevating the urine $\mathrm{pH}$. As mentioned above, urinary tract infections may be secondary to sexual intercourse. Moreover, benign prostatic enlargement, urethral strictures, neurogenic bladder dysfunction and pelvic organ prolapse contribute to bladder outlet obstruction, causing urinary stasis as well as increased infection rates. ${ }^{26}$ In women, the short length of the urethra also makes urinary tract infections common.

This finding corroborates earlier findings ${ }^{5,6}$ which recorded that a significant number of stone diseases in Nigeria were secondary to obstruction, infection and immobilization. Patients with infection stones have a high incidence of new stone growth and persistent infection, especially if residual stone fragments remain, hence the importance of complete eradication of these organisms needs constant emphasis. ${ }^{27}$

The high occurrence of calcium-containing stones is also similar to that recorded in other studies. ${ }^{12,16,28}$

However, the low occurrence of calcium oxalate stones in this study differs from the usual picture seen in Caucasians $^{29,30}$ where calcium oxalate stones form the greater percentage of stones. This is not surprising due to the correspondingly high prevalence of infection stones among the study population. As mentioned earlier, urease activity produces ammonia and renders the urine alkaline, which in turn favours the formation of calcium phosphate stones.

The risk factors for calcium stone formation ${ }^{31,32,33,34}$ range from hypercalciuria, chronic low urine output, hyperpara- thyroidism, to renal tubular acidosis. There is evidence that the degree of hypercalciuria is worsened by high dietary sodium intake, high animal protein intake, and loop diuretics. A study of 120 Italian hypercalciuric calcium oxalate stone patients has demonstrated that a diet with normal calcium, low sodium, and low animal protein resulted in reduced incidence of calcium stones compared with those on a low-calcium diet. ${ }^{35}$

With abundance of health tips freely available on social media currently, many stone formers may feel the need to decrease calcium in their diet due to the predominance of calcium in urinary tract stones thereby worsening the process. Hence, proper individualized patient counselling and health education based on the stone composition of an individual is advocated in this regard.

Apart from chemical analysis of stones, management should also include urine culture and anti-microbial sensitivity testing which should be obtained every 1 or 2 months during the first year, and at regular intervals thereafter. Urine electrolytes and other tests indicated by the patient's general condition may also be necessary.

\section{Conclusion}

Calcium and struvite stones constitute the commonest components of uroliths in this study. Hence, effective clinical management with complete eradication of the causative organisms, proper individualized patient counselling with emphasis on diet and lifestyle measures are necessary for prevention of stone recurrence and generally improving the quality of life of the patients. This study is based on simple qualitative chemical analysis which is cost effective for patients, feasible and adaptable to the level of manpower available in a developing country.

However, with the existence of more modern methods like Fourier-transform infrared spectroscopy (FT-IR) and $\mathrm{X}$-ray diffraction (XRD) which are beyond the capacities existent in resource-limited countries like Nigeria, more work is needed in this area in order to further highlight steps which may be necessary in effective management.

\section{Conflict of interest}

The authors declare no conflict of interest.

\section{Authors' contributions}

IAM and MCU conceived and designed the study protocol; IAM, SOE and EOA collected the data, performed 
data entry and data analysis. IAM and MCU handled data interpretation. All authors critically revised the manuscript for intellectual content. All authors read and approved the final manuscript.

\section{Acknowledgement}

Special thanks to the staff of Chemical pathology and Surgery departments of the University of Nigeria Teaching Hospital for all their support, co-operation and encouragement in the course of this study.

\section{References}

1. Romero V, Akpinar H, Assimos GD. Kidney Stones: A Global Picture of Prevalence, Incidence, and Associated Risk Factors. Rev Urol. 2010; 12 (2/3): e86-e96.

2. Scales CD, Smith AC, Hanley JM, Saigal CS. Urologic Diseases in America Project. Prevalence of kidney stones in the United States. Eur Urol. 2012; 62(1):160-165.

3. Hesse A, Brändle E, Wilbert D, Köhrmann K.-U, Alken P. Study on the Prevalence and Incidence of Urolithiasis in Germany Comparing the Years 1979 vs. 2000. Eur Urol. 2003; 44(6):709-713.

4. Osegbe DN. The rise in urolithiasis in Nigeria. BMJ. 1987; 295:19-26.

5. Mbonu O, Attah C, Ikeakor I. Urolithiasis in an African population. Int Urol Nephrol. 1984; 16:291-296.

6. Monu JU. Pattern of urolithiasis in Benin City, Nigeria. J Natl Med Assoc 1989; 81(6): 695-698.

7. Delaney MP, Price CP, Lamb EJ. Kidney Disease. In: Burtis CA, Ashwood ER, Bruns DE, editors. Tietz textbook of clinical chemistry and molecular diagnostics. $5^{\text {th }}$ ed. USA: Elsevier, 2012: 1523-1608.

8. Stamatelou KK, Francis ME, Jones CA, Nyberg LM, Curhan GC. Time trends in reported prevalence of kidney stones in the United States: 1976-1994. Kidney Int. 2003; 63:1817-1823.

9. Gillen DL, Worcester EM, Coe FL. Decreased renal function among adults with a history of nephrolithiasis: a study of NHANES III. Kidney Int 2005; 67:685-690.

10. McIntosh JF, Salter RW. The qualitative examination of urinary calculi. J Clin Invest. 1942; 21(6):751-754.

11. Klufio GO, Bentsi IK, Yeboah ED, Quartey JK. Upper urinary tract stones in Accra, Ghana. West African Journal of Medicine. 1996; 15(3): 173-176.

12. Mshelia DS, Gali BM, Naaya UH, Habu SA. Chemical composition of urinary calculi in Maiduguri, Nigeria. Afr J Med Med Sci. 2005; 34(2):185-188.

13. Wathigo FK, Hayombe A, Maina D. Urolithiasis analysis in a multiethnic population at a tertiary hospital in Nairobi, Kenya. BMC Res Notes. 2017;10(1):158.

14. Oliech JS, Kayima JK, Otieno LS. Urinary tract stone disease in Nairobi. East Afr Med J. 1998;75(1):30-4.

15. Rahman A, Danish KF, Zafar A, Ahmad A, Chaudhry AR. Chemical Composition of Non Infected Upper Urinary Tract Calculi. Rawal Med J. 2008; 33(1):54-55

16. Jarrar BM, AL-Enazi MM, Al-Messar S. Chemical composition of urinary calculi from Al-jouf province of Saudi Arabia. JRMS. 2007; 14(3): 15-19.

17. Channa NA, Ghangro AB, Soomro AM, Noorani L. Analysis of kidney stones by FTIR spectroscopy, JLUMHS. 2007; 2:66-73.

18. Nicolle LE, Harding GKM, Preiksaitis J, Ronald AR. The Association of Urinary Tract Infection with Sexual Intercourse. J Infect Dis. 1982; 146 (5): 579-583.

19. Moore EE, Hawes SE, Scholes D, Boyko EJ, Hughes JP, Fihn SD. Sexual Intercourse and Risk of Symptomatic Urinary Tract Infection in Post-Menopausal Women. J Gen Intern Med 2008; 23(5): 595-599.

20. Roudakova K, Monga M. The evolving epidemiology of stone disease. Indian J Urol. 2014; 30(1): 44-48.

21. Nowfar S, Palazzi-Churas K, Chang DC, Sur RL. The relationship of obesity and gender prevalence changes in United States inpatient nephrolithiasis. Urology. 2011; 78: 1029-1033.

22. Chukwuonye II, Chuku A, John C et al. Prevalence of overweight and obesity in adult Nigerians - a systematic review. Diabetes Metab Syndr Obes. 2013; 6: 43-47.

23. Akarolo-Anthony SN, Willet WC, Spiegelman D, Adebamowo CA. Obesity epidemic has emerged among Nigerians. BMC Public Health. 2014; 14:455.

24. Desalu OO, Salami AK, Oluboyo PO, Olarinoye JK. Prevalence and socio-demographic determinants of obesity among adults in an urban Nigerian population. Sabel Medical Journal. 2008; 11(2):61-64.

25. Schwartz BF, Stoller ML. The vesical calculus. Urol Clin N Am. 2000; 27: 333-34.

26. Douenias R, Rich M, Badlani G, Mazor D, Smith A. Predisposing factors in bladder calculi. Review of 100 cases. Urology. 1991; 37: 240-243.

27. Silverman DE, Stamey TA. Management of infection 
stones: the Stanford experience. Medicine. 1983, 62(1):44 51.

28. Altaf J, Arain AH, Kella NL, Rehman S. Chemical Analysis of Urinary Stones and its Locations Associated to Urinary Tract. JLUMHS. 2013; 12(3): 203-207.

29. Thomas Knoll. Epidemiology, Pathogenesis, and Pathophysiology of Urolithiasis. Eur Urol Suppl. 2010; 9: 802-806.

30. Taylor EN, Curhan GC. Oxalate Intake and the Risk for Nephrolithiasis. JASN. 2007; 18(7): 2198-2204.

31. Preminger GM, Sakhaee K, Skurla C, Pak CY. Prevention of recurrent calcium stone formation with potassium citrate therapy in patients with distal renal tubular acidosis. The Journal of Urology. 1985; 134(1):20-23.
32. Evan AE, Lingeman JE, Coe FL, Miller NL, Bledsoe SB, Sommer AJ et al. Histopathology and surgical anatomy of patients with primary hyperparathyroidism and calcium phosphate stones. Kidney Int. 2008; 74, (2): 223-229. 33. Broadus AE, Horst RL, Lang R, Littledike ET, Rasmussen $\mathrm{H}$. The Importance of Circulating 1,25-Dihydroxyvitamin D in the Pathogenesis of Hypercalciuria and Renal-Stone Formation in Primary Hyperparathyroidism. N Engl J Med. 1980; 302:421-426.

34. Coe FL, Parks JH. Stone Disease in Hereditary Distal Renal Tubular Acidosis. Ann Intern Med. 1980; 93(1_ Part_1):60-61.

35. Borghi L, Schianchi T, Meschi T, et al. Comparison of two diets for the prevention of recurrent stones in idiopathic hypercalciuria. N Engl J Med. 2002; 346: 77-84. 